\title{
Studies on Menthol Derivatives
}

\section{Part II. Application of NMR Spectroscopy for Configurational Analysis of (-)-Menthyl Carbinol and Related Compounds ${ }^{\dagger}$}

\author{
By Atushi Kato, Hiroo UedA* and Yohei Hashimoto \\ The Kobe Women's College of Pharmacy, Motoyama, Kobe \\ *Department of Agricultural Chemistry, College of Agriculture, University \\ of Osaka Prefecture, Sakai \\ Received February 16, 1970
}

In a previous paper, "1he authors have reported the synthesis of (-)-menthyl carbinol from (-)-menthol. This paper reports the stereochemical structure of (-)-menthyl carbinol particularly with respect to the $\mathrm{C}_{3}$-position as ellucidated by NMR spectral analyses. The configuration of (-)-menthyl carbinol(1 - (R) - methyl-3-(R)-hydroxymethyl-4-(S)-isopropylcyclohexane) was established in similar studies by using NMR spectra of menthols ${ }^{21}$

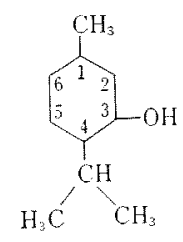

and their derivatives. ${ }^{31}$

Each isomer of menthols investigated exists in four preferred conformation ${ }^{4,5)}$ as shown in Table I.

These isomers of menthol and their deriva-

$\dagger$ This report was presented at the 19th Kansai branched Meeting of the Pharmaceutical Society of Japan at Osaka, October 1969.

1) A. Kato, H. Ueda and Y. Hashimoto, Agr. Biol. Chem., 34, 28 (1970).

2) H. Leda and S. Shimizu, ibid., 23, 376 (1959).

3) H. Ueda, ibid., 24, 506 (1960).

t) H. Feltkamp and N.C. Franklin, Tetrahedron, 21, 1541 (1965).

5) B.J. Armitage, G. W. Kenner M. J. T. Robinson, ibid, 20,747 (1964).
TABLE I.

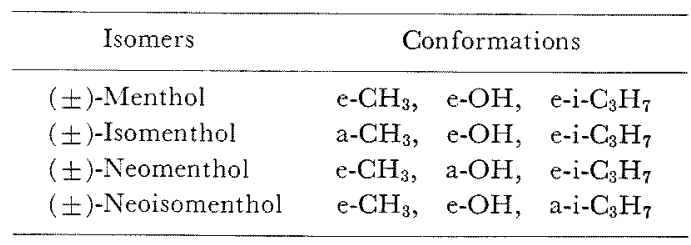

tives can be classified into two series (eseries and a-series) according to the signal pattern and chemical shift of the methyl group in NMR spectra (Figs. 1, 2). The conformations of e-series all have equatorial substituents at the $\mathrm{C}_{1}-, \mathrm{C}_{3^{-}}$and $\mathrm{C}_{4}$-positions ((-)-menthol and its derivatives). On the other hand, those of a-series have more than one axial substituent (Isomenthol, Neomenthol, Neoisomenthol and their derivatives). It was found that the signal patterns and chemical shifts of $\mathrm{CH}_{3}$ and $\mathrm{i}-\mathrm{C}_{3} \mathrm{H}_{7}$ in NMR spectra were clearly different between e- and a-series as shown in Figs. 1, 2. In a-series the hydrogen resonance absorption peaks of the methyl and isopropyl groups shifted to lower field than those of e-series. ${ }^{6 \sim 8}$ The chemical

6) Y. Kawazoe, Y. Sato, M. Natsume, H. Hasegawa, T. Okamoto and K. Tsuda, Chem. Pharm. Bull., 10, 338 (1962).

7) A. D. Buckingham, Canad. J. Chem., 38, 300 (1960).

8) J. C. Jacquesy, J. M. Lehn and J. Levisalles, Bull. Soc. chin. France, 1961, 2444. 


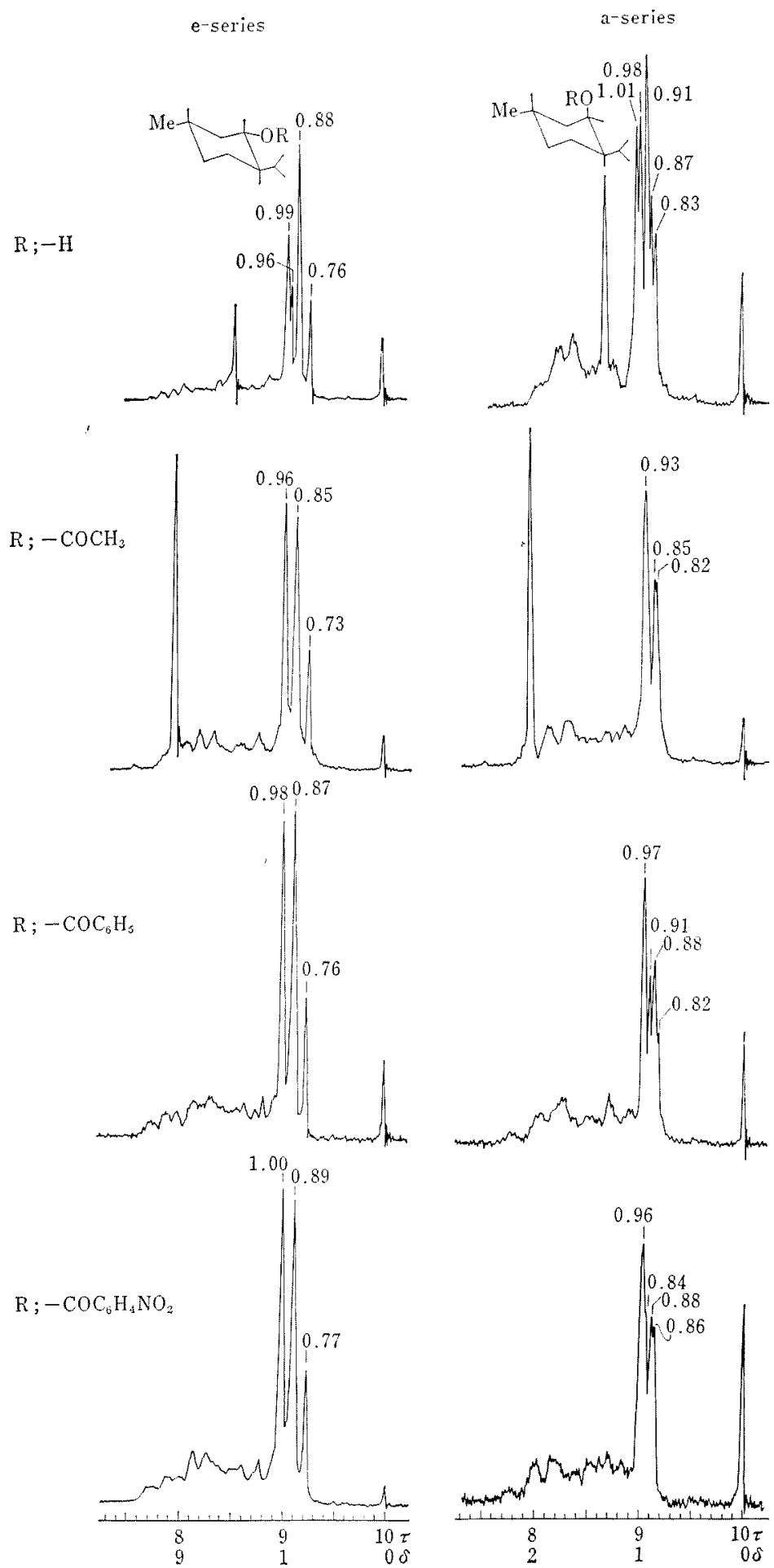

FIG. 1. NMR Spectra of e-Series $((-)$-menthol and its derivatives) and a-Series $((+)$-neomenthol and its derivatives). 

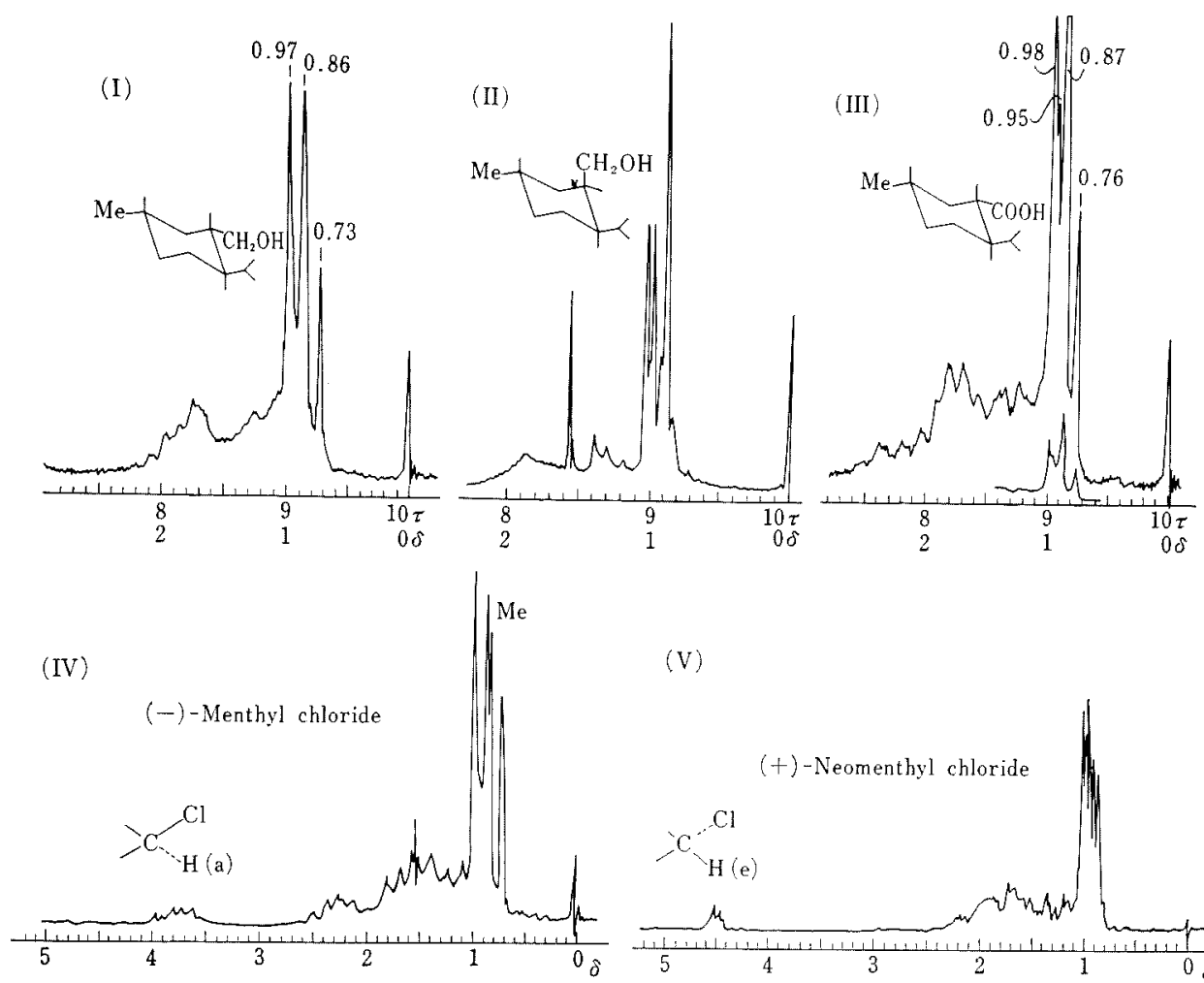

(V)

FIG. 2. NMR Spectra of (-)-Menthyl Carbinol (I), (+)-Neomenthyl Carbinol (II), (-)-3-p-Menthane Carboxylic Acid (III), (I)-Menthyl Chloride (IV), and (+)-Neomenthyl Chloride (V).

TABLE II.

\begin{tabular}{lc}
\hline \multicolumn{1}{c}{ e-Series } & $\begin{array}{c}\text { oppm (chemical shift } \\
\text { of signal in the } \\
\text { highest field) }\end{array}$ \\
\hline (-)-Menthol & 0.76 \\
(-)-Menthyl acetate & 0.73 \\
(-)-Menthyl benzoate & 0.76 \\
(-)-Menthyl-p-nitrobenzoate & 0.77 \\
(-)-Menthyl chloride & 0.73 \\
(-)-Menthyl carbinol & 0.73 \\
(-)-3-p-Menthane carboxylic acid & 0.76 \\
a-Series & \\
(+)-Neomenthol & 0.83 \\
(+)-Neomenthyl acetate & 0.82 \\
(+)-Neomenthyl benzoate & 0.82 \\
(+)-Neomenthyl-p-nitrobenzoate & 0.86 \\
(+)-Neomenthyl chloride & 0.84 \\
(+)-Neomenthyl carbinol & 0.83 \\
(+)-Isomenthol & 0.83 \\
(+)-Isomenthyl- $p$-nitrobenzoate & 0.85 \\
(+)-Neoisomenthyl- $p$-nitrobenzoate & 0.88 \\
(-)-Neoisomenthyl-3,5-dinitrobenzoate & 0.90
\end{tabular}

shifts of the methyl hydrogen resonance absorption peak in the highest field in each compound were presented in Table II.

The difference of this chemical shift was caused by diamagnetic anisotropy which depends on the orientation of the bond with respect to the applied magnetic field (shieding and deshieding effect).

The signal patterns and the chemical shifts of (-)-menthyl carbinol and its derivative (3-P-methane carboxylic acid) surely belong to e-series. On the other hand, those of (t)neomenthyl carbinol(epimer) belong to a-series (Fig. 3). Consequently, it is evident that the former had an equatorial carbinol group at the $\mathrm{C}_{3}$-position. These results support the configuration of (-)-methyl carbinol(1-(R)methyl-3-(R)-hydroxymethyl-4-(S)-isopropylcyclohexane) which was assigned on the basis 

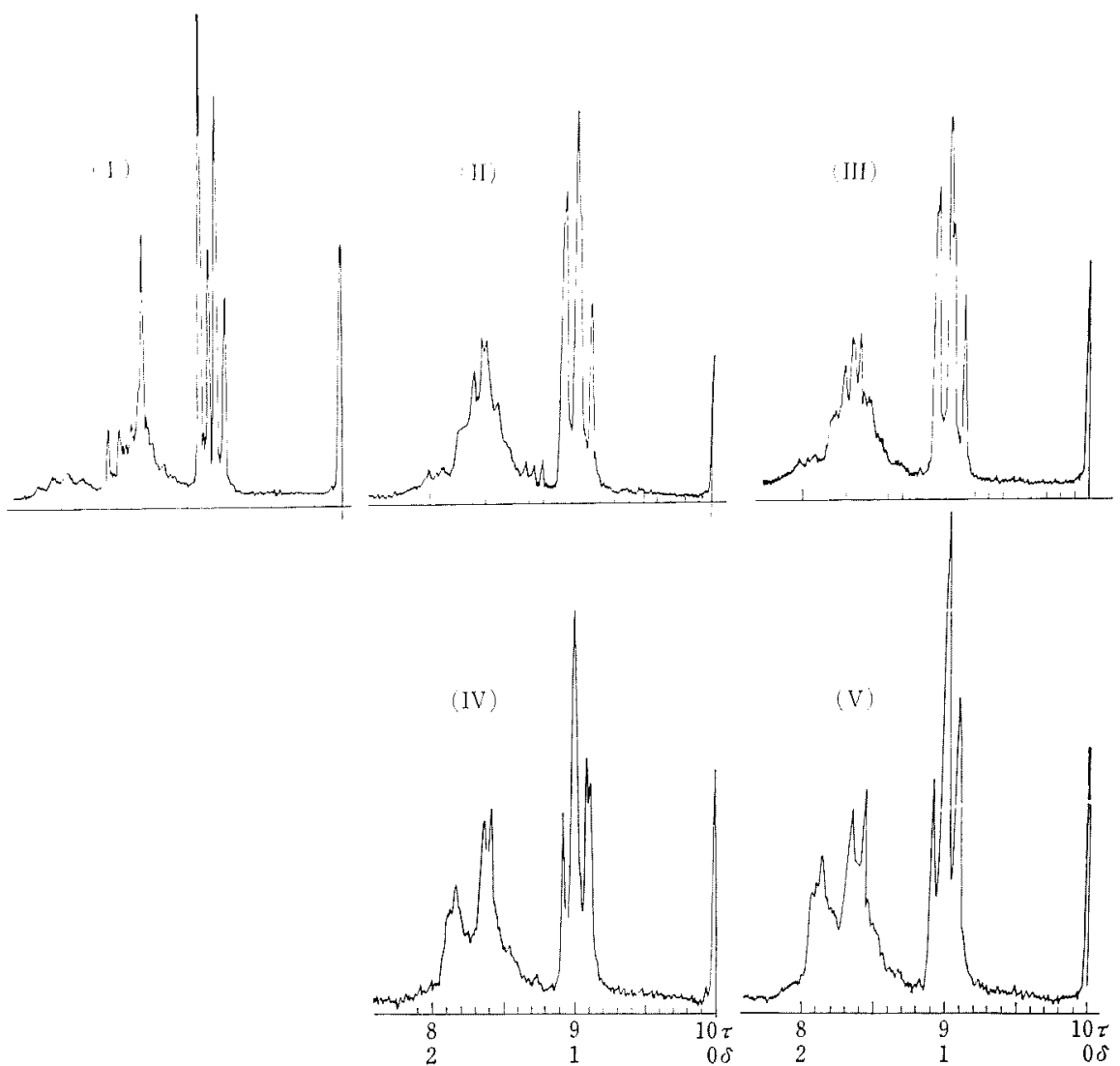

FIG. 3. NMR Spectra of cis- $p$-Menthane Derivatives.

$(+)$-Isomenthol (I), (+)-Isomenthyl-p-nitrobenzoate (II), ( \pm )-Isomenthyl- $p$-nitrobenzoate (III), (+)-Neoisomenthyl-p-nitrobenzoate (IV), (-)-Neoisomenthyl-3,5-dinitrobenzoate (V).

of chemical analyses in the previous report. For configurational analysis of other menthan compounds NMR spectroscopy is useful.

\section{EXPERIMENTAL}

All melting and boiling points were uncorrected. NMR spectra were obtained with a Varian A-60A NMR spectrometer at the fixed frequency of $60 \mathrm{Mc}$. in carbon tetrachloride and benzene containing tetramethylsilane (TMS) as an internal reference.

(-)-Menthol and its derivatives. (-)-Menthol, $\mathrm{mp}$ $42.5 \sim 43.0^{\circ} \mathrm{C},[\alpha]_{\mathrm{D}}^{20}-50.0^{\circ} \mathrm{C}(c=2.00$ in chloroform); (-)-Menthyl acetate, bp $83.0 \sim 84.0^{\circ} \mathrm{C} / 5 \mathrm{~mm}, d_{4}^{20} 0.929$, $[\alpha]_{D}^{20}-73.32(c=2.001$ in chloroform). (-)-Menthyl benzoate, $\mathrm{mp} \quad 54.5^{\circ} \mathrm{C}, \quad[\alpha]_{\mathrm{D}}^{16}-87.1^{\circ} \quad(c=1.97 \quad$ in methanol); (-)-Menthyl-p-nitrobenzoate, $\mathrm{mp} 62.0^{\circ} \mathrm{C}$, $[\alpha]_{\mathrm{D}}^{16}-76.0 \quad(c=1.82$ in methanol); (-)-Menthyl chloride, bp $78 \sim 80^{\circ} \mathrm{C} / 12 \mathrm{~mm}, n_{\mathrm{D}}^{30} 1.4589,[\alpha]_{\mathrm{D}}^{30}-46.0$ (neat).

$$
\text { (+)-Neomenthol and its derivatives. (+)-Neomenthol, }
$$
bp $83 \sim 84^{\circ} \mathrm{C} / 14 \mathrm{~mm},[\alpha]_{D}^{10}+18.02^{\circ}$ (neat); (+)-Neomenthyl acetate, bp $82 \sim 83^{\circ} \mathrm{C} / 5 \mathrm{~mm}, n_{\mathrm{D}}^{23} 1.6515,[\alpha]_{\mathrm{D}}^{23}+$ $22.44^{\circ}(c=2.002$ in methanol); ( + -Neomenthyl benzoate, bp $148 \sim 149^{\circ} \mathrm{C} / 5 \mathrm{~mm},[\alpha]_{\mathrm{D}}^{20}+103.4^{\circ} \quad(c=0.116$ in methanol); ( + -Neomenthyl-p-nitrobenzoate, $\mathrm{mp}$ $96 \sim 97^{\circ} \mathrm{C},[\alpha]_{\mathrm{D}}^{10}+18.1^{\circ}(c=2.005$ in chloroform). ( + )Neomenthyl chloride, bp $58 \sim 65^{\circ} \mathrm{C} / 9 \mathrm{~mm},[\alpha]_{\mathrm{D}}^{20}+54.5^{\circ}$ $(c=2.003$ in methanol).

(-)-Menthyl carbinol, (-)-3-p-menthane carboxylic acid, 
!d (t)-neomenthyl carbinol. (-)-Menthyl carbinol, , $105 \sim 111^{\circ} \mathrm{C} / 11 \mathrm{~mm}, n_{\mathrm{D}}^{30} 1.4646,[\alpha]_{\mathrm{D}}^{30}-39.62^{\circ}$ (neat); snzoate of (-)-menthyl carbinol, bp $168 \sim 169^{\circ} \mathrm{C} / 5$ $\mathrm{m},[\alpha]_{\mathrm{D}}^{20}-27.2^{\circ}(c=0.624$ in methanol).

$p$-Nitro benzoate of $(-)$-menthyl carbinol, mp $85 \sim$ $j^{\circ} \mathrm{C},[\alpha]_{\mathrm{D}}^{20}-44.99^{\circ}$ ( $c=13.56$ in chloroform).

(-)-3-p-Menthane carboxylic acid, mp $66 \sim 67^{\circ} \mathrm{C}$, ]$_{\mathrm{D}}^{30}-60.00^{\circ} \quad(c=2.00$ in methanol $)(+)-\mathrm{Neo}$ enthyl carbinol; Pure $(+)$-neomentbyl carbinol was tained from the $(+)$-menthyl ester of (+)-3-penthane carboxylic acid by reduction. This ester as separated from a mixture of the methyl esters -)-3-p-menthane and (+)-3-p-menthane carboxylic ;ids by preparative gas-chromatography. bp $87 \sim$ $1{ }^{\circ} \mathrm{C} / 8 \mathrm{~mm}, \quad[\alpha]_{\mathrm{D}}^{20}+10.5^{\circ} \quad(c=2.02$ in chloroform $)$ 5-Dinitrobenzoate; mp $97 \sim 99^{\circ} \mathrm{C}$. Anal. Found: C, 1.55; $\mathrm{H}, 6.73$. Calcd. for $\mathrm{C}_{17} \mathrm{H}_{20} \mathrm{O}_{6} \mathrm{~N}_{2}: \mathrm{C}$, 59.41; , 6.640. Preparative gas-chromatography was carried out using a $8 \mathrm{~mm} \times 2.5 \mathrm{~m}$ column packed with polyethylene glycol $20 \mathrm{M}$ in Toyo P-1. Column Temp. $105^{\circ} \mathrm{C}$, Flow rate $60 \mathrm{ml} / \mathrm{min}$.

cis-p-Menthane derivatives. (t)-Isomenthol, mp $82.5^{\circ} \mathrm{C}, \quad[\alpha]_{\mathrm{D}}^{20}+25.9^{\circ}(c=1.56$ in chlorofor $\mathrm{m})$.

$(+)$-Isomenthyl-p-nitrobenzoate, $\operatorname{mp} 54.0^{\circ} \mathrm{C} . \quad[\alpha]_{\mathrm{D}}^{20}$ $+24.9^{\circ}(c=2.00$ in chloroform). (t)-Neoisomenthyl$p$-nitrobenzoate, mp $73^{\circ} \mathrm{C} .[\alpha]_{\mathrm{D}}^{15}+2.95^{\circ}(c=2.002$ in chloroform). (-)-Neoisomenthyl-3,5-dinitrobenzoate, $\operatorname{mp} 99.5^{\circ} \mathrm{C} . \quad[\alpha]_{D}^{15}-5.0^{\circ}(c=1.98$ in chloroform).

Acknowledgement. The authors are indebted to Dr. Y. Sasaki, Faculty of Pharmaceutical Science, Osaka University, for his kind advice and guidance. They also wish to express their sincere thanks to Dr. K. Morita, Takeda Chemical Industries, Ltd. and Miss Suzuki, Faculty of Pharmaceutical Science, Osaka University, for NMR spectra. 